\title{
Nuestro lema: "La Biotecnología, aliada estratégica en la recuperación agroindustrial post COVID-19"
}

\author{
Daynet Sosa del Castillo
}

DOI. 10.21931/RB/2021.06.01.1

espués de la pandemia nos dimos cuenta de que el sector agrícola nunca detuvo sus actividades, que todos necesitamos de los productos que nuestros agricultores cosechan y hoy más que nunca estamos viendo a la ciencia en general y a la biotecnología en particular, no como resultado final sino como un proceso de colaboración entre los científicos y la industria para aportar soluciones tecnológicas y creativas a este problema urgente en el cual estamos inmersos como humanidad.

En este marco conceptual, el V CIBB 2020 - modalidad virtual renovó el esfuerzo que a lo largo de 15 años ha venido realizando la ESPOL a través de su centro de Biotecnología (CIBE) en la promoción de la biotecnología ecuatoriana; evento que se constituyó en la continuación de los Congresos I CIBB 2012, II CIBB 2014, III CIBB 2016 y IV CIBB 2018, igualmente heredero de una elevada calidad y excelencia académica; y celebrado con total éxito durante los días 5, 6, 7 y 8 de octubre del presente año. Congreso coorganizado por la Asociación de exportadores de banano del Ecuador (AEBE) y realizado en paralelo a la XVII Convención internacional del banano.

A esta convocatoria asistieron más de 200 personas, entre investigadores, estudiantes, empresarios y organismos del Estado. Los ponentes invitados, 15 expertos nacionales y 30 internacionales, todos ellos de gran prestigio científico a nivel mundial realizaron sus ponencias sobre temas de punta en biotecnología, tales como genómica, proteómica, organismos transgénicos, micropropagación, productos nutracéuticos, valorización de residuos, fitobiomas, control biológico, biodiversidad nativa y bioeconomía, entre otros temas.

El evento, además, fue un punto de encuentro entre la academia y el sector productivo, permitiendo, a través de la iniciativa "Science Match", el intercambio de experiencias y el establecimiento de alianzas estratégicas que impulsen el aprovechamiento de la biotecnología para mejorar la competitividad de las cadenas productivas. Esta iniciativa, que nació en el año 2018, tiene como propósito estimular, a la par de la difusión de investigación, el contacto directo entre quienes producen el conocimiento y quienes lo asimilan, con vistas a ir propiciando la tan necesaria y desconocida transferencia de la biotecnología agrícola al sector productivo pues como CIBE, somos portadores de soluciones para los desafíos del sector productivo. Este año las categorías de expertos para citas fueron Agricultura y agroindustria, Categoría Alimentos, Química y ambiente e Innovación tecnológica, lo que arrojó un total de 6 citas agendadas con acuerdos de seguimiento para un futuro relacionamiento. Aunado a ello, la realización de la II reunión de socios de la red CYTED-BIOALI, permitió establecer un enlace internacional no solo entre académicos sino también, de empresarios extranjeros y nacionales que apuestan por la incorporación cada vez mayor de la biotecnología, en el sector cacao y banano.

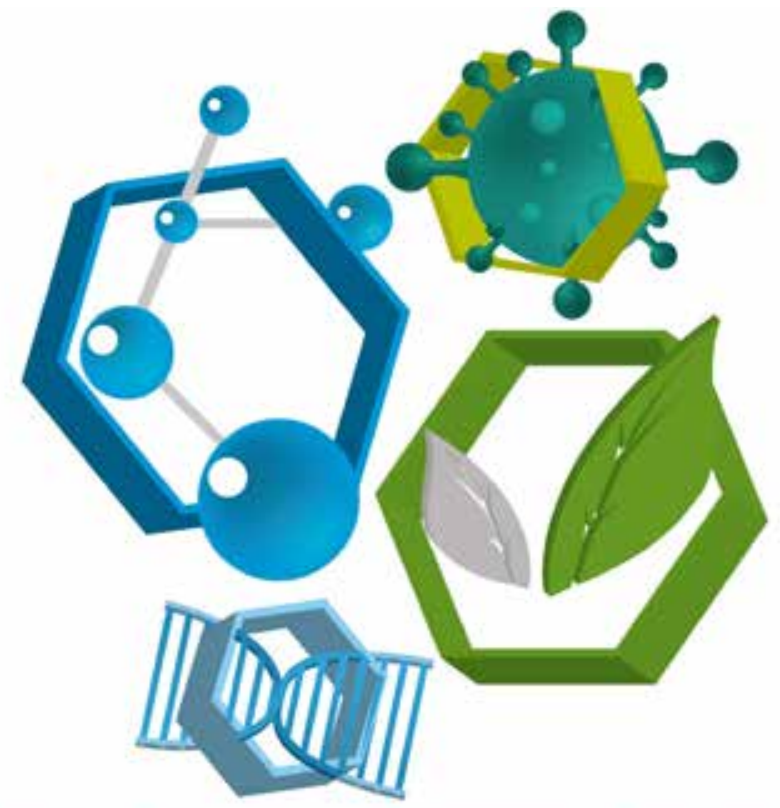

V CONGRESO INTERNACIONAL DE BIOTECNOLOGIA Y BIODIVERSIDAD 2020

"LA BIOTECNOLOGIA, ALIADA ESTRATÉGICA EN LA RECUPERACIÓN AGROINDESTRLAL POST COVID-19". 

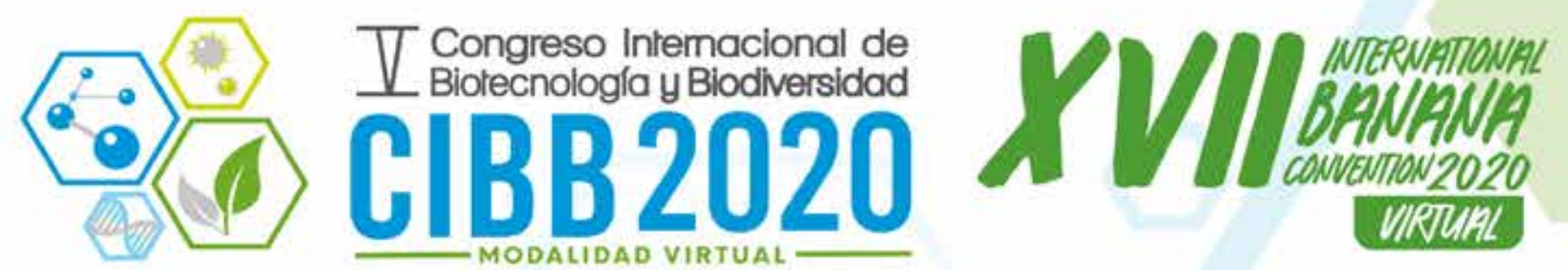

\section{AlianZa estratégica PARA SEgUIR AVANZANDO EN TIEMPO DE PANDEMIA}
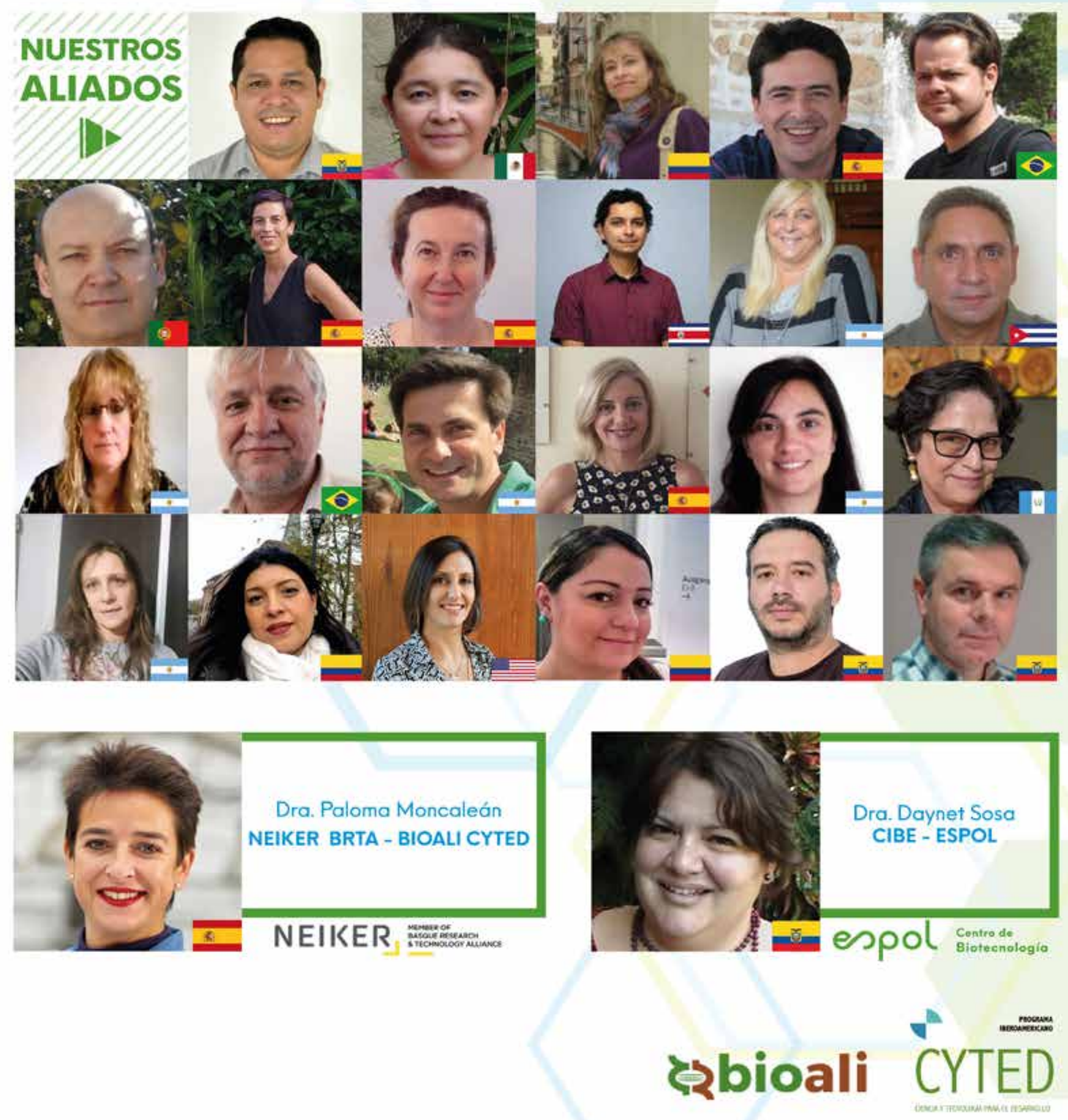
Adicionalmente, se realizó un curso post congreso: "Tecnologías y aplicaciones en el agregado de valor de la madera", en modalidad virtual, durante los días 13, 14 y 15 de octubre, sin ningún costo para los 29 participantes registrados, cuyo objetivo fue mostrar las nuevas tecnologías y enfoques disponibles para el mejoramiento de especies forestales y el agregado de valor de la madera.

Dentro del evento se presentaron 70 trabajos, en modalidad de audio cartel, (69 nacionales y 11 internacionales) divididos en tres áreas o sesiones: Avances científicos en Banano y Cacao, Biotecnología y Biodiversidad y Tecnología Limpias y Bioproductos. En cada una de ellas se mostraron avances de investigación y puntos de vista de los investigadores del CIBE y de representantes de 14 instituciones académicas del Ecuador y 7 internacionales, lo cual muestra el alcance de nuestro evento en el país y la región. En cada una de las sesiones se premió al mejor trabajo de investigación y además se contó con la presentación de algunos casos exitosos de relacionamiento empresa- investigación a nivel regional.

Si bien el tema central y compartido con el Foro internacional del banano fueron los avances en la mejora genética del cultivo y la importancia del debate nacional sobre un programa nacional de mejora genética, este espacio científico nos permitió también debatir sobre otros productos como el cacao, y temas esenciales para el sector productivo como los procesos de fermentación para la obtención del chocolate. Abordamos también las problemáticas del arroz desde el punto de vista agrícola y comercial, y pusimos a disposición del público nuestros logros en materia de fertilizantes orgánicos.

Hemos de mencionar el apoyo que recibimos por parte de nuestro coorganizador y auspiciantes: AEBE, Red CYTED-BIOALI, programa CEDIA, a VLIR-NETWORK Ecuador y a Gustavo Venegas Representaciones así como de la ESPOL y su Gerencia de comunicaciones. Expresamente mencionar la difusión científica de este evento a través de las redes sociales, el libro de memorias así como la posibilidad de publicar en la revista BIONATURA los mejores trabajos científicos presentados en cada sesión.

Antes de finalizar quisiera agradecer y reconocer el arduo y valioso esfuerzo del Comité organizador y comité científico del CIBB, agradecer la participación de los 204 asistentes a la plataforma virtual, a cada uno de los ponentes, al equipo editorial de BIONATURA y a todos aquellos que hicieron posible la realización del Congreso, evento que en su quinta edición nos ha reafirmado la importancia de ir de la mano con el sector privado para encontrar soluciones a problemas y caminar juntos a la innovación que tanto necesita el país para su desarrollo productivo.

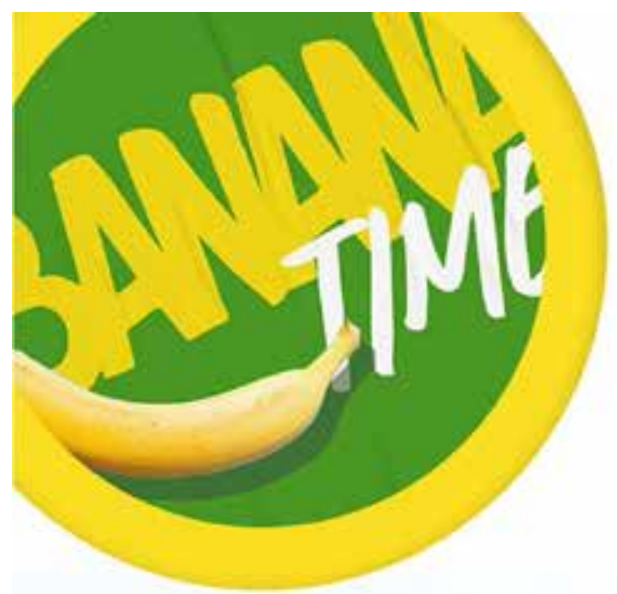

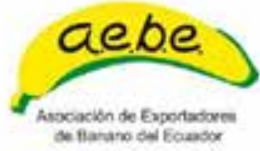

CIBB2020

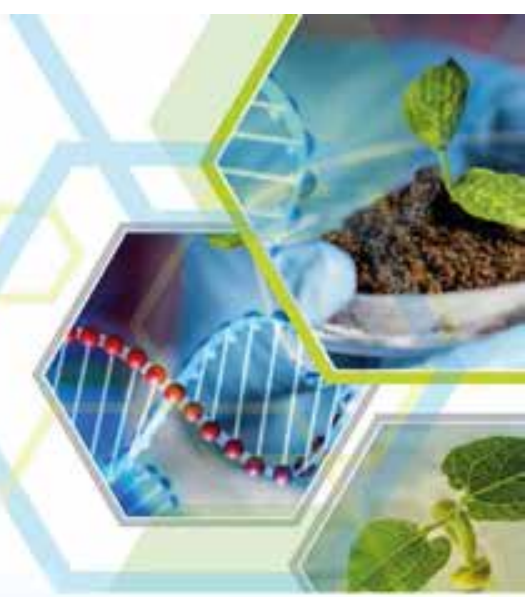

5 de Octubre de $\mathbf{2 0 2 0}$

Inciamos otra etapa en eventos

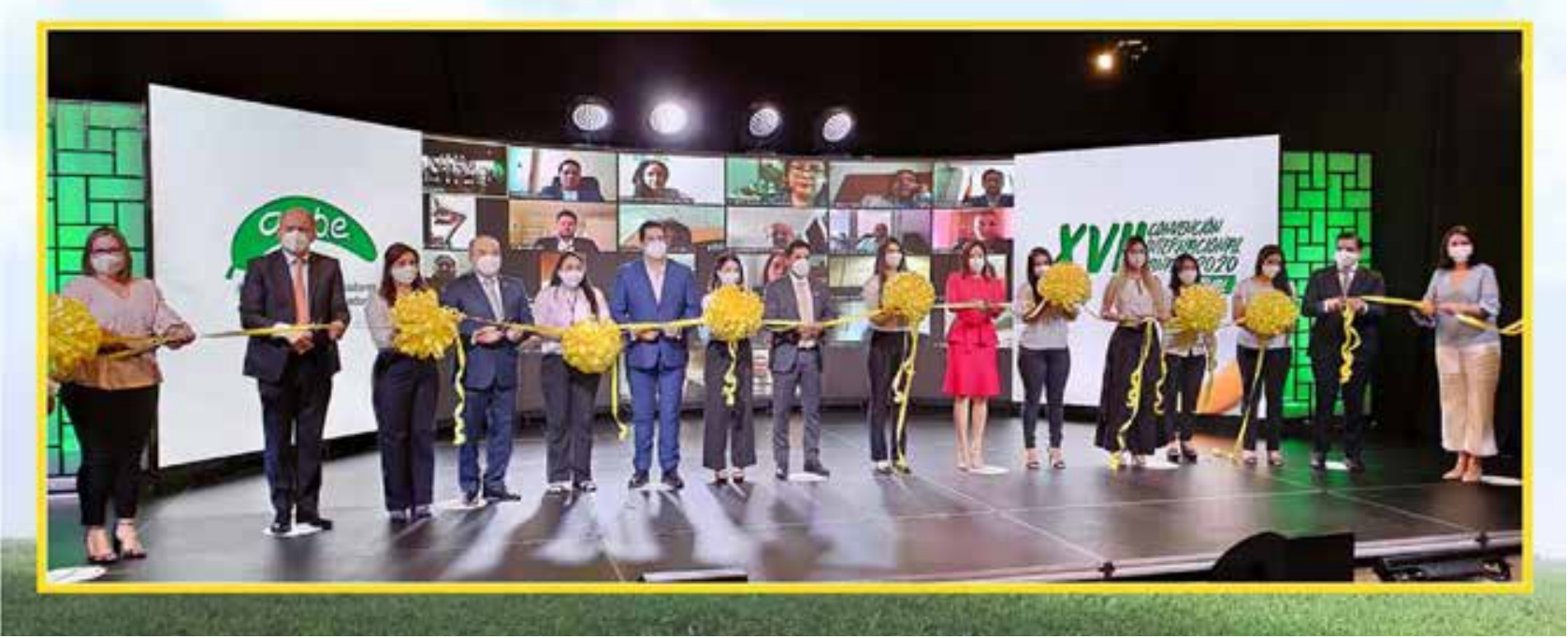

